\title{
Dexamethasone and Citicoline Mitigate Cisplatin- Induced Peripheral Neuropathy: A Novel Experimental Study in Mice
}

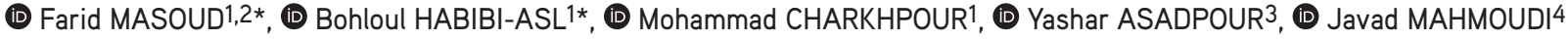 \\ 1 Tabriz University of Medical Sciences, Faculty of Pharmacy, Department of Pharmacology, Tabriz, Iran \\ 2Radboud University Medical Center, Radboud Institute for Molecular Life Sciences, Nijmegen, Netherlands \\ 3 Tabriz University of Medical Sciences, Student Research Committee and Faculty of Pharmacy, Tabriz, Iran \\ 4 Tabriz University of Medical Sciences, Neurosciences Research Center, Tabriz, Iran
}

\begin{abstract}
Objectives: Given the rising prevalence of cisplatin-induced peripheral neuropathy (CisIPN), investigations to alleviate its adverse effects are required. Oxidative stress and free radical development are essential pathways of CisIPN. Specifically, dexamethasone and citicoline are characterized by anti-inflammatory and antioxidant activities that might reduce CisIPN incidence and severity. The current study assessed the possible impacts of novel interventions, dexamethasone, and, citicoline on CisIPN.

Materials and Methods: Seventy-two male mice were randomly allocated into nine groups (n: 8/each group). Different doses of dexamethasone $(7.5,15,30 \mathrm{mg} / \mathrm{kg}$, i.p.), citicoline (10, 20, $40 \mathrm{mg} / \mathrm{kg}$, i.p.), and the combination (dexamethasone $7.5 \mathrm{mg} / \mathrm{kg}+$ citicoline $10 \mathrm{mg} / \mathrm{kg}$, i.p.) were injected in the first three days and one day before receiving cisplatin $(2 \mathrm{mg} / \mathrm{kg}$, i.p.). The tail-flick method was used for assessing nociception. Besides, malondialdehyde (MDA), interleukin-1 beta (IL-1 $\beta$ ), tumor necrosis factor- $\alpha$ (TNF- $\alpha$ ), total antioxidant capacity (TAC), and mice weight differences $(\triangle \mathrm{W})$ were measured.

Results: Different doses of dexamethasone and citicoline enhanced latency time ( $p<0.05)$. Moreover, dexamethasone $15 \mathrm{mg} / \mathrm{kg}$ diminished the level of MDA and increased TAC ( $p<0.05$ ) and in $30 \mathrm{mg} / \mathrm{kg}$, MDA was reduced ( $p<0.05$ ). Besides, 20 and $40 \mathrm{mg} / \mathrm{kg}$ of citicoline reduced MDA and elevated TAC ( $p<0.05)$, and $10 \mathrm{mg} / \mathrm{kg}$ merely reduced MDA ( $p<0.05)$. Dexamethasone in all doses declined IL-1 $\beta$ and TNF- $\alpha$ levels, and citicoline only at 40 $\mathrm{mg} / \mathrm{kg}$ lessened their levels ( $p<0.05$ ). Interestingly, $\Delta \mathrm{W}$ declined more in the dexamethasone and citicoline groups than the cisplatin group ( $p<0.05$ ). Conclusion: Dexamethasone and citicoline attenuate CisIPN through anti-inflammatory activity, improving the antioxidant capacity, and inhibiting lipid peroxidation.
\end{abstract}

Key words: Cisplatin, citicoline, dexamethasone, oncology, peripheral neuropathy

\section{INTRODUCTION}

Peripheral neuropathy is driven by an injury to the peripheral nervous system and can originate from various factors, such as diabetes mellitus, vitamin insufficiency, autoimmune diseases, and particular medications.,2

Unquestionably, chemotherapy-induced peripheral neuropathy (CIPN) is the most frequent medication-IPN that has occurred predominantly with platinum-based drugs, and it affects approximately half of the patients, who received these medications. ${ }^{3,4}$ Although the incidence of its symptoms is determined by numerous factors such as the drug's physicochemical properties, dose, duration, liver function, and age, the intolerable symptoms usually persist for several weeks after the drug discontinuation. ${ }^{5}$

Cisplatin (cis-diamminedichloroplatinum II) has been administered to treat several solid malignancies, such as ovarian, lung, and testicular carcinomas. ${ }^{6}$ However, serious side effects, including neurotoxicity, ototoxicity, and nephrotoxicity, affect patients' quality of life, may lead to treatment discontinuation, and consequently, its clinical usage has been limited. ${ }^{7,8}$ Specifically, CisIPN symptoms are associated with sensory disturbances that occur more frequently than autonomic and

*Correspondence: habibiaslbohlool@gmail.com, habibib@tbzmed.ac.ir, - faridmasoud@gmail.com, farid.masoud@ru.nl, Phone: +98 (411) 3341315, +31 644915009,

ORCID-ID: orcid.org/0000-0001-8427-9149, orcid.org/0000-0003-1823-3702

Received: 15.07.2021, Accepted: 19.10.2021

๑Turk J Pharm Sci, Published by Galenos Publishing House. 
movement signs; its hallmarks are incorporated weakness in the hands, gait disturbance, weakness in movements, orthostatic hypotension, and altered sexual activity.9.10 Interestingly, the exact mechanism of CisIPN has not been determined; however, some studies have indicated that pro-inflammatory cytokines, especially tumor necrosis factor- $\alpha$ (TNF- $\alpha$ ) and interleukin-1 beta (IL-1 $\beta$ ), lipid peroxidation, and oxidative stress may demonstrate the accelerated factors in the incidence of CisIPN. ${ }^{11-13}$

Given the potential anti-inflammatory, antioxidant, and neuroprotective activities of dexamethasone and citicoline ${ }^{14-19}$ and the lack of a study in this area, we hypothesized that they might act as potential agents to diminish CisIPN occurrence and/or severity. Insights into these aspects are expected to understand dexamethasone and citicoline impacts on CisIPN better. This research has shown the possible prophylactic effects of dexamethasone and citicoline on CisIPN.

\section{MATERIALS AND METHODS}

\section{Drugs and chemicals}

Cisplatin was provided by Pfizer Inc. (NY, USA). Dexamethasone and citicoline were supplied by Iran Darou Pharmaceutical Co.
(Tehran, Iran). Thiobarbituric acid, hydrogen peroxide, $n$-butanol, and phosphoric acid, were obtained from Sigma-Aldrich Inc. (Missouri, USA). Ketamine and xylazine were also purchased from Alfasan Diergeneesmiddelen B.V. (Utrecht, Netherlands).

\section{Animals}

Healthy male mice (25-35 g) were purchased from Tabriz University of Medical Sciences Animal Center, housed in a standard polypropylene cage at $25 \pm 2^{\circ} \mathrm{C}$ temperature, and provided 12 hour light/12 hour dark intervals with ad libitum feeding. Tabriz University of Medical Sciences Ethics Committee authorized the study protocols and methods (ethical code: IR.TBZMED.VCR.REC.1398.087, May 13, 2019), conformed to the NIH Guide for the Care and Use of Laboratory Animals ( $8^{\text {th }}$ edition, NRC 2011).

\section{Experimental design}

Seventy-two mice were randomly divided into the following nine groups (n: 8/each group) (Figure 1).

(1) Control: The animals received sterile saline $(10 \mathrm{~mL} / \mathrm{kg}$, i.p.) for three consecutive days and the fourth, seventh, eleventh, fourteenth, eighteenth, twenty-first, and twenty-fifth days.

(2) Cisplatin: The animals in the first three days and the sixth,

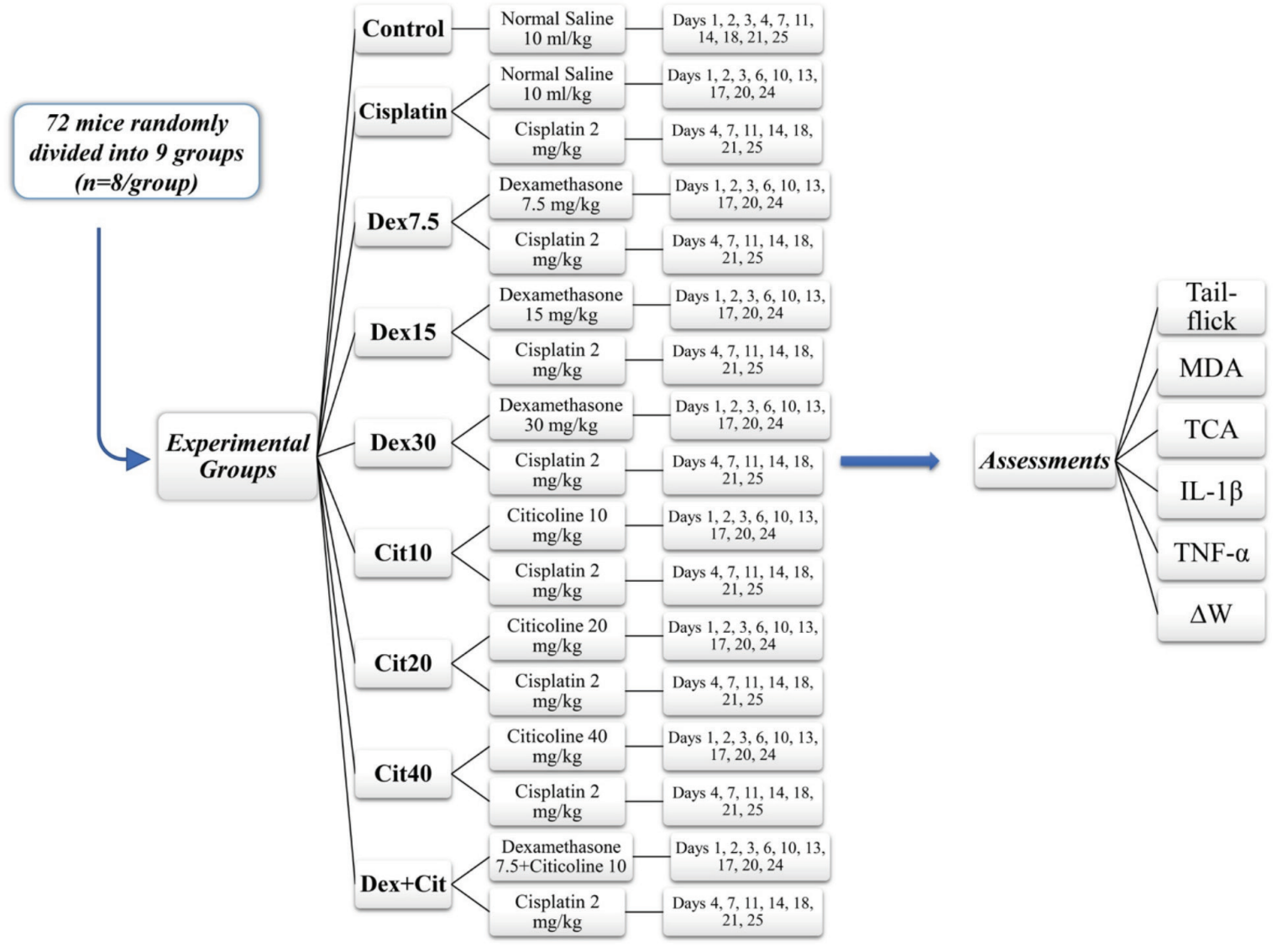

Figure 1. Functional diagram of the experimental groups and the assessments. In all figures, Dex7.5, dexamethasone $7.5 \mathrm{mg} / \mathrm{kg}$; Dex15, dexamethasone 15 mg/kg; Dex30, dexamethasone 30 mg/kg; Cit10, citicoline 10 mg/kg; Cit20, citicoline 20 mg/kg; Cit40, citicoline 40 mg/kg; and Dex + Cit, dexamethasone 7.5 $\mathrm{mg} / \mathrm{kg}$ and citicoline $10 \mathrm{mg} / \mathrm{kg}$

Dex: Dexamethasone, Cit: Citicoline, Dex + Cit: Dexamethasone $7.5 \mathrm{mg} / \mathrm{kg}$ and citicoline $10 \mathrm{mg} / \mathrm{kg}$, MDA: Malondialdehyde, IL-1 $\beta$ : Interleukin-1 beta, TNF- $\alpha$ : Tumor necrosis factor- $\alpha$, TAC: Total antioxidant capacity, $\Delta \mathrm{W}$ : Mice weight differences 
tenth, thirteenth, seventeenth, twentieth, and twenty-fourth days received sterile saline $10 \mathrm{~mL} / \mathrm{kg}$, i.p.). Additionally, cisplatin was injected ( $2 \mathrm{mg} / \mathrm{kg}$, i.p.) on the fourth, seventh, eleventh, fourteenth, eighteenth, twenty-first, and twenty-fifth days.

(3) Dex7.5: The animals in the first three days and the sixth, tenth, thirteenth, seventeenth, twentieth, and twenty-fourth days received dexamethasone $(7.5 \mathrm{mg} / \mathrm{kg}$, i.p.). Besides, on the fourth, seventh, eleventh, fourteenth, eighteenth, twenty-first, and twenty-fifth days, cisplatin $2 \mathrm{mg} / \mathrm{kg}$, i.p. was administered.

(4) Dex15: The interventions were identical to those of the Dex7.5 group; however, the dexamethasone dosages were 15 $\mathrm{mg} / \mathrm{kg}$.

(5) Dex30: Similar to the conditions in the Dex7.5 group except that the dexamethasone dosages were $30 \mathrm{mg} / \mathrm{kg}$.

(6) Cit10: Same procedure as the Dex7.5 group, but instead of dexamethasone, citicoline $10 \mathrm{mg} / \mathrm{kg}$ was administered.

(7) Cit20: Identical procedure as the Dex7.5 group, but instead of dexamethasone, $20 \mathrm{mg} / \mathrm{kg}$ of citicoline was injected.

(8) Cit40: The conditions were similar to those in the Dex7.5 group, but $40 \mathrm{mg} / \mathrm{kg}$ of citicoline was injected instead of dexamethasone.

(9) Dex + Cit: The conditions were the same as those in the Dex7.5 group; however, instead of dexamethasone, combinations of dexamethasone $7.5 \mathrm{mg} / \mathrm{kg}$ and citicoline 10 $\mathrm{mg} / \mathrm{kg}$ were administered.

In all study groups, the latency time to pain was measured using the tail-flick test on day 0 (before interventions) and repeated on the days fourth, eleventh, eighteenth, twenty-fifth, and twenty-eighths.

\section{Nociception assessment}

In the tail-flick method, the thermal light $\left(235 \mathrm{~mW} / \mathrm{cm}^{2}\right.$ and $50^{\circ} \mathrm{C}$ temperature) created by a lamp beam (20\% intensity) from a constant distance to the $3-4 \mathrm{~cm}$ of animal's tail end in a special chamber (Ugo Basile 37360 Stoelting Co., IL, USA). The latency time (in seconds) was identified as the elapsed time between the beginning of the tail exposure to the thermal source and its withdrawal. ${ }^{20}$ In this study, the maximum time, when the heat stimulus was applied to the animal's tail (cut-off time), was determined for 30 seconds to avoid tail tissue injury. Besides, stimulation was applied to successive sites from the end to the tail's beginning to increase accuracy.

\section{Assessment total antioxidant capacity (TAC)}

TAC evaluation was based on ABTS radical reduction and was performed according to the technique by Miller et al. ${ }^{21}$ using a commercial kit (Rel Assay Diagnostics, Türkiye). The results were expressed in millimoles per liter ( $\mathrm{mmol} / \mathrm{L})$.

\section{Measurement of malondialdehyde (MDA)}

MDA calculation was started by dissolving $500 \mu \mathrm{L}$ of serum into $3 \mathrm{~mL}$ of $1 \%$ phosphoric acid. It was applied to the test tube after vortexing $1 \mathrm{~mL}$ of $0.67 \%$ thiobarbituric acid solution, and after full vortexing, it was put for $45 \mathrm{~min}$ in a laboratory water bath. The test tubes were cooled under cold water after the necessary time; $3 \mathrm{~mL}$ of normal butanol was applied and vortexed for 2 min, centrifuged for 10 minutes at 3000 rpm; eventually, the supernatant was collected for calculating light absorbance at $532 \mathrm{~nm} .{ }^{22}$ The results were reported in nanomoles per liter (nmol/L).

\section{Weight changes}

The animal weights were measured at baseline (day 0 ) and repeated on days 7,14 , and 28 by an analytical balance (Libror AEU-210, Shimadzu, Japan); their weight changes for each study group were recorded and compared.

\section{Assay of proinflammatory cytokines}

Mice were anesthetized intraperitoneally (i.p.) by administering a combination of ketamine $(50 \mathrm{mg} / \mathrm{kg})$ and xylazine $(5 \mathrm{mg} / \mathrm{kg})$; blood samples were obtained from their abdominal aorta and centrifuged at $10000 \mathrm{rpm}$ for 10 minutes at $4^{\circ} \mathrm{C}$ and collected supernatants were frozen at $-80^{\circ} \mathrm{C}$ to measure the levels of proinflammatory cytokines. Subsequently, TNF- $\alpha$ and IL- $1 \beta$ levels were assessed using ELISA kits (Bender Medsystems, Vienna, Austria). Briefly, in a 96 well plate, $50 \mathrm{~mL}$ of standard were inserted, polyclonal antibodies were separately added to all wells, and their surfaces were coated and incubated at room temperature $\left(25^{\circ} \mathrm{C}\right)$ for $2 \mathrm{~h}$. Followed by washing, the wells were filled with streptavidin-HRP and incubated at room temperature. Afterward, a colored product parallel to the amount of IL-1 $\beta$ and TNF- $\alpha$ in the sample was formed by adding tetramethylbenzidine substrate solution to all wells. Finally, to prevent the enzymereaction, the stop solution was applied to each well, and the relative absorbance of TNF- $\alpha$ and IL-1 $\beta$ were measured spectrophotometrically at $450 \mathrm{~nm}$ (Synergy HT, BioTek, USA). The results were standardized to the amount of protein in each sample and expressed as a picograms per milligram (pg/mg) of protein. $^{23}$

\section{Statistical analysis}

Statistical analyses were conducted using SPSS software 25 (SPSS Inc., Chicago, Illinois). Data from experiments are presented as mean \pm standard errors of means. An ANOVA test with Tukey post-hoc analysis was used to assess the various treatment regimens' efficacy between the study groups. A $p<0.05$ value was assumed to demonstrate a statistically significant difference.

\section{RESULTS}

\section{Different interventions and CisIPN}

The comparative effects of different interventions on CisIPN pain hypersensitivity are presented in Figure 2. Cisplatin injection in the cisplatin group on days 25 and 28 significantly diminished the latency time compared with the control group ( $p<0.01$ ) (Figure 2A). Administration of dexamethasone with 7.5 and 15 and $\mathrm{mg} / \mathrm{kg}$ (Dex7.5 and Dex15 groups) on days 11, 18, 25, and 28 ( $p<0.001$ ) and $30 \mathrm{mg} / \mathrm{kg}$ (Dex30 group) on the fourth day $(p<0.05)$ and days 25 and 28 ( $p<0.001)$ could significantly increased the latency time to pain compared with cisplatin group (Figure 2B). Besides, citicoline $10 \mathrm{mg} / \mathrm{kg}$ on the fourth day ( $p<0.01$ ) and on days 11, 18, 25, and 28 ( $p<0.001)$, also at doses 
20 and $40 \mathrm{mg} / \mathrm{kg}$ on days $28,25,18,11$ ( $p<0.001$ ) substantially increased pain latency time compared to the cisplatin group (Figure 2C). Moreover, co-administration of dexamethasone and citicoline (Dex + Cit group) on days 11 ( $p<0.01), 18$ ( $p<0.05), 25$, and 28 ( $p<0.001)$ dramatically improved latency time compared with cisplatin group; however, on day 28 ( $p<0.01$ ) compared with dexamethasone group (Dex7.5) and on days 11 and 25 ( $p<0.01$ ), 18 and 28 ( $p<0.001)$ in comparison with citicoline group (Cit10) the latency time was declined (Figure 2D).

\section{Changes in mice weights}

Administration of cisplatin in the cisplatin group reduced body weight differences $(\Delta \mathrm{W})$ compared to the control group (-1.07 \pm 0.09 vs. $0.14 \pm 0.11 ; p>0.05)$. Also, dexamethasone at doses of 7.5 and 30 (Dex7.5 and Dex30 groups) decreased $\Delta \mathrm{W}$ significantly compared to the cisplatin group $(-3.03 \pm 0.2 \mathrm{vs}$. $-1.07 \pm 0.09$; $p<0.001$, and $-6.29 \pm 0.45$ vs. $-1.07 \pm 0.09 ; p<0.001$, respectively). However, citicoline at all doses declined $\Delta \mathrm{W}$ meaningfully compared to the cisplatin group (Cit10, $-5.57 \pm 0.01$ vs. -1.07 $\pm 0.09 ; p<0.001$, Cit20, $-4.34 \pm 0.07$ vs. $-1.07 \pm 0.09 ; p<0.001$, and Cit40, $-3.11 \pm 0.55$ vs. $-1.07 \pm 0.09 ; p<0.01$ ). Moreover, the combination of dexamethasone and citicoline (Dex + Cit group) reduced $\Delta \mathrm{W}$ notably compared with the cisplatin group (-4.5 \pm 0.25 vs. $-1.07 \pm 0.09 ; p<0.001)$, Cit10 group ( $-4.5 \pm 0.25$ vs. -5.57 $\pm 0.01 ; p<0.001)$, and Dex7.5 group ( $-4.5 \pm 0.25$ vs. $-3.03 \pm 0.2$; $p<0.01$ ) (Table 1).

\section{TAC and MDA levels}

Cisplatin administration in the cisplatin group increased MDA significantly compared to the control group ( $2.52 \pm 0.28 \mathrm{vs} .1 .64$ $\pm 0.09 ; p<001)$. The injection of dexamethasone $(7.5,15$, and 30 $\mathrm{mg} / \mathrm{kg}$ ) elevated TAC and declined MDA levels compared to the cisplatin group; however, only at the $15 \mathrm{mg} / \mathrm{kg}$ (Dex15 group) showed significant differences $(p<0.05)$. Also, the reduced MDA level in the Dex30 group was meaningfully compared the cisplatin group ( $p<0.05$ ). Similarly, citicoline at all doses elevated TAC and diminished MDA levels compared to the cisplatin group; notably, this outlined changes occurred at doses $10 \mathrm{mg} / \mathrm{kg}$ (TAC, $0.57 \pm$ 0.05 vs. $0.54 \pm 0.04 ; p>0.05, \mathrm{MDA}, 1.46 \pm 0.08$ vs. $2.52 \pm 0.28$; $p<0.01$ ), $20 \mathrm{mg} / \mathrm{kg}$ (TAC, $0.75 \pm 0.04$ vs. $0.54 \pm 0.04 ; p<0.05$, MDA, $1.73 \pm 0.17$ vs. $2.52 \pm 0.28 ; p<0.05$ ), and $40 \mathrm{mg} / \mathrm{kg}$ (TAC, $0.82 \pm 0.04$ vs. $0.54 \pm 0.04 ; p<0.001, \mathrm{MDA}, 1.8 \pm 0.15$ vs. 2.52 \pm 0.28 ; $p<0.05$ ). Moreover, co-administration of dexamethasone and citicoline (Dex + Cit group) enhanced TAC and reduced MDA
A

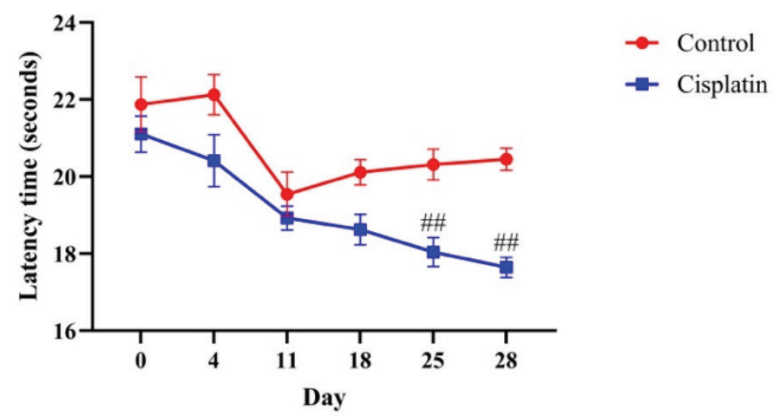

C
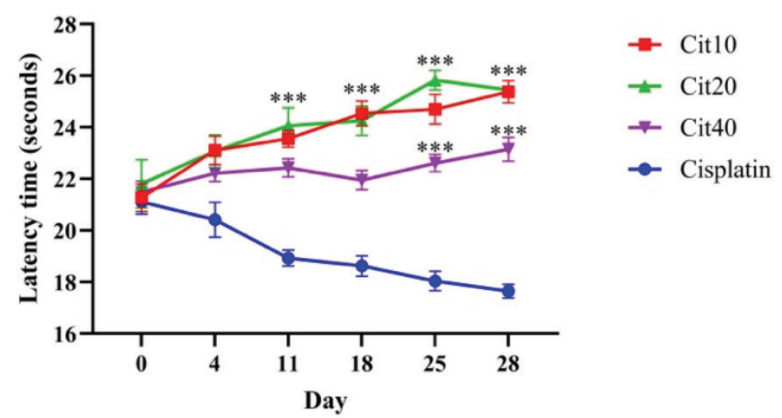

B

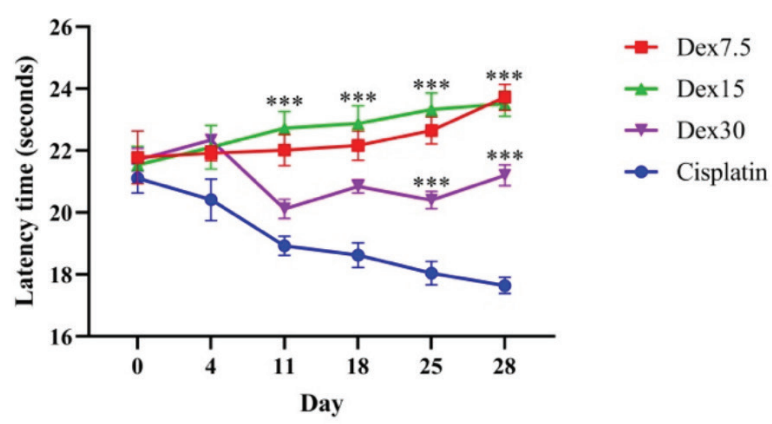

D

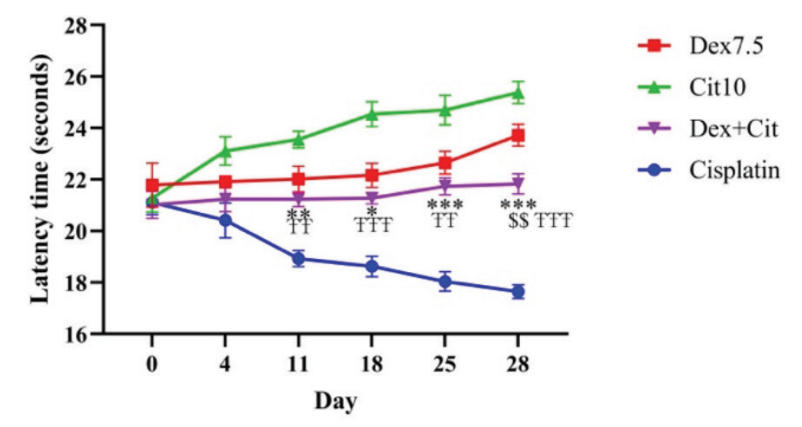

Figure 2. The effect of different interventions on latency times in study groups. (A) Comparison between the control and cisplatin group. (B) Comparing dexamethasone injected groups (Dex7.5, Dex15, Dex30, and Dex + Cit) with the cisplatin group. (C) Comparing with citicoline injected groups (Cit10, Cit20, Cit40, and Dex + Cit) and the cisplatin group. (D) Comparison of the combination group (Dex + Cit) with Dex7.5 and Cit10 groups. Data are provided as mean \pm SEM (n: 8/each group). Statistical analyses were conducted using one-way ANOVA with Tukey post-hoc analysis

${ }^{*} p<0.05,{ }^{* *} p<0.01,{ }^{* * *} p<0.001$ compared with the cisplatin group. ${ }^{\# \#} p<0.01$ as compared with the control group. ${ }^{\$ \$} p<0.01$ as compared with the Dex7.5 group. ${ }^{\mp 7} p<0.01$ and ${ }^{\mathrm{FF}} p<0.001$ as compared with the Cit10 group. Dex: Dexamethasone, Cit: Citicoline, Dex + Cit: Dexamethasone $7.5 \mathrm{mg} / \mathrm{kg}$ and citicoline $10 \mathrm{mg} / \mathrm{kg}$, SEM: Standard error of means 
levels compared with the cisplatin group $(0.69 \pm 0.05$ vs. $0.54 \pm$ $0.04 ; p<0.05$ and $1.55 \pm 0.21$ vs. $2.52 \pm 0.28 ; p<0.05$, respectively) (Table 2).

TNF- $\alpha$ and IL-1 $\beta$ levels

Figure 3 shows that TNF- $\alpha$ levels in the cisplatin group were significantly enhanced compared with the control group ( $p<0.01$ ). The administration of dexamethasone at doses 7.5 $\mathrm{mg} / \mathrm{kg}$ (Dex7.5), $15 \mathrm{mg} / \mathrm{kg}$ (Dex15), and $30 \mathrm{mg} / \mathrm{kg}$ (Dex30) significantly declined the TNF- $\alpha$ levels compared with the cisplatin group ( $p<0.05, p<0.05$, and $p<0.01$, respectively). Besides, citicoline showed a considerable reduction at dose 40 $\mathrm{mg} / \mathrm{kg}$ (Cit40) compared with the cisplatin group ( $p<0.05$ ). The combination of dexamethasone and citicoline (Dex + Cit) did not demonstrate significant TNF- $\alpha$ levels change compared to the cisplatin group; nonetheless, its levels diminished considerably compared with the Cit10 group ( $p<0.05)$.

As shown in Figure 4, the IL-1 $\beta$ level was significantly enhanced in the cisplatin group compared to the control group ( $p<0.001$ ). Additionally of dexamethasone at all doses $7.5 \mathrm{mg} / \mathrm{kg}$ (Dex7.5), $15 \mathrm{mg} / \mathrm{kg}$ (Dex15), and $30 \mathrm{mg} / \mathrm{kg}$ (Dex30), significantly diminished the IL-1 $\beta$ levels compared with the cisplatin group ( $p<0.01, p<0.01$, and $p<0.001$, respectively). Moreover, citicoline only at dose $40 \mathrm{mg} / \mathrm{kg}$ indicated a significant reduction in IL-1 $\beta$ level compared with the cisplatin group ( $p<0.05$ ). Combination of dexamethasone and citicoline (Dex + Cit) did not reveal IL$1 \beta$ changes considerably than the cisplatin group; however, its levels decremented significantly compared with the Cit10 group $(p<0.01)$.

Table 1. Changes in mice weights between study groups

\begin{tabular}{|c|c|c|c|c|c|}
\hline Groups & Day 0 & Day 7 & Day 14 & Day 28 & $\Delta \mathrm{W}$ \\
\hline Control & $28 \pm 1.44$ & $29.57 \pm 1.41$ & $28.71 \pm 1.47$ & $28.14 \pm 1.33$ & $0.14 \pm 0.11$ \\
\hline Cisplatin & $27.28 \pm 0.68$ & $27.28 \pm 0.56$ & $26.85 \pm 0.63$ & $26.21 \pm 0.77$ & $-1.07 \pm 0.09$ \\
\hline Dex7.5 & $30.12 \pm 1.5$ & $28.37 \pm 1.33$ & $28.12 \pm 1.29$ & $27.09 \pm 1.3$ & $-3.03 \pm 0.2^{\star \star *}$ \\
\hline Dex15 & $26.85 \pm 0.34$ & $26 \pm 0.81$ & $25.57 \pm 1.13$ & $23.81 \pm 1.35$ & $-3.04 \pm 1.01^{\star *}$ \\
\hline Dex30 & $33.14 \pm 0.4$ & $31.85 \pm 0.4$ & $28.07 \pm 0.78$ & $26.85 \pm 0.85$ & $-6.29 \pm 0.45^{\star * \star}$ \\
\hline Cit10 & $28.14 \pm 1.31$ & $26.71 \pm 1.2$ & $25.14 \pm 1.12$ & $22.57 \pm 1.32$ & $-5.57 \pm 0.01^{\star \star \star}$ \\
\hline Cit20 & $27.5 \pm 0.61$ & $25.83 \pm 0.6$ & $24.08 \pm 0.63$ & $23.16 \pm 0.54$ & $-4.34 \pm 0.07^{\star * \star}$ \\
\hline Cit40 & $29.14 \pm 1.03$ & $27.57 \pm 1.2$ & $27.12 \pm 1.3$ & $26.03 \pm 1.58$ & $-3.11 \pm 0.55^{\star \star}$ \\
\hline Dex + Cit & $25.83 \pm 1.24$ & $25.66 \pm 1.4$ & $23.33 \pm 1.54^{\$}$ & $21.33 \pm 1.49^{\$ \$}$ & $-4.5 \pm 0.25^{\star \star *, \$ \$, ~ \mp F+}$ \\
\hline
\end{tabular}

Data are provided as mean \pm SEM, g. $n:$ 8/each group. [ $\triangle \mathrm{W}$ : Weight changes $\left(\mathrm{W}_{\text {in day } 28}-\mathrm{W}_{\text {in day }}{ }_{0}\right.$ ]. Dex: Dexamethasone, Cit: Citicoline, Dex + Cit: Dexamethasone $7.5 \mathrm{mg} /$ $\mathrm{kg}$ and citicoline $10 \mathrm{mg} / \mathrm{kg}$. ${ }^{* \star} p<0.01$ and ${ }^{* \star \star} p<0.001$ as compared with the cisplatin group. ${ }^{\$} p<0.05$ and ${ }^{\$ s} p<0.01$ as compared with the Dex7.5 group. ${ }^{\text {in }} p<0.001$ as compared with the Cit10 group, SEM: Standard error of means

\section{Table 2. TAC and MDA levels in the study groups}

\begin{tabular}{lll} 
Groups & TAC $(\mathrm{mmol} / \mathrm{L})$ & MDA $(\mathrm{nmol} / \mathrm{L})$ \\
\hline Control & $0.6 \pm 0.02$ & $1.64 \pm 0.09$ \\
\hline Cisplatin & $0.54 \pm 0.04$ & $2.52 \pm 0.28^{\# \#}$ \\
\hline Dex7.5 & $0.58 \pm 0.03$ & $2.02 \pm 0.3$ \\
\hline Dex15 & $0.65 \pm 0.03^{\star}$ & $1.85 \pm 0.16^{*}$ \\
\hline Dex30 & $0.66 \pm 0.37$ & $1.65 \pm 0.06^{\star}$ \\
\hline Cit10 & $0.57 \pm 0.05$ & $1.46 \pm 0.08^{* *}$ \\
\hline Cit20 & $0.75 \pm 0.04^{*}$ & $1.73 \pm 0.17^{\star}$ \\
\hline Cit40 & $0.82 \pm 0.04^{\star \star *}$ & $1.8 \pm 0.15^{\star}$ \\
\hline Dex + Cit & $0.69 \pm 0.05^{\star}$ & $1.55 \pm 0.21^{*}$ \\
\hline
\end{tabular}

Data are presented as mean \pm SEM. n: 8/each group. Dex: Dexamethasone, Cit10: Citicoline, Dex + Cit: Dexamethasone $7.5 \mathrm{mg} / \mathrm{kg}$ and citicoline $10 \mathrm{mg} /$ kg. ${ }^{*} p<0.05,{ }^{* *} p<0.01$, and ${ }^{* * *} p<0.001$ as compared with the cisplatin group. \#\# $p<0.01$ as compared with the control group, SEM: Standard error of means, TAC: Total antioxidant capacity, MDA: Malondialdehyde

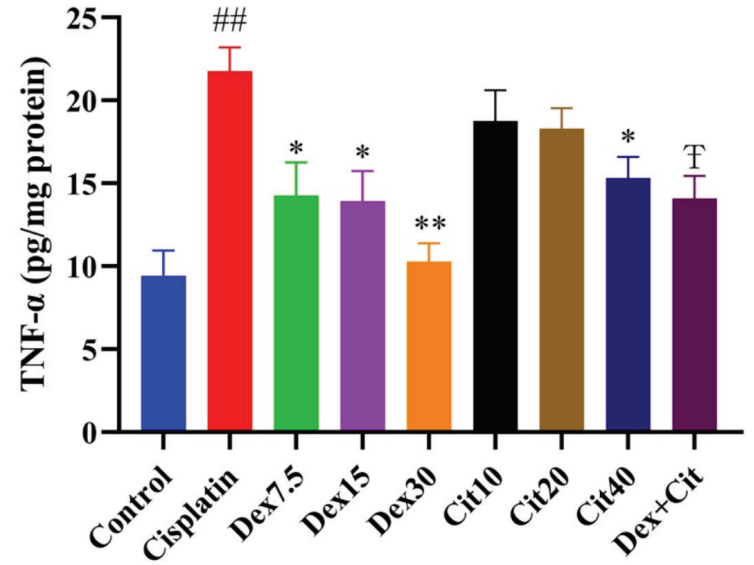

Groups

Figure 3. The levels of TNF- $\alpha$ in different groups. Data are presented as mean \pm SEM ( $n: 8 /$ each group)

${ }^{*} p<0.05$ and ${ }^{* *} p<0.01$ compared with the cisplatin group. ${ }^{\# \# p<0.01 \text { as }}$ compared with the control group. ${ }^{\mp} p<0.05$ as compared with the Cit10 group, Dex: Dexamethasone, Cit: Citicoline, Dex + Cit: Dexamethasone $7.5 \mathrm{mg} / \mathrm{kg}$ and citicoline $10 \mathrm{mg} / \mathrm{kg}$, SEM: Standard error of means, TNF- $\alpha$ : Tumor necrosis factor- $\alpha$ 


\section{DISCUSSION}

The effectiveness of different doses of dexamethasone and citicoline on CisIPN in healthy male mice was evaluated. Administration of dexamethasone in different doses indicated a significant preventive effect on raising latency times at doses 7.5 and $15 \mathrm{mg} / \mathrm{kg}$ from the eleventh day, and in $30 \mathrm{mg} /$ $\mathrm{kg}$ dose from the $25^{\text {th }}$ day, compared with the cisplatin group. Citicoline in all doses significantly increased the latency time from the $11^{\text {th }}$ day than the cisplatin group. Moreover, coadministration of dexamethasone and citicoline (Dex + Cit group) indicated their significant protective effects from the $11^{\text {th }}$ day compared to the cisplatin and Cit10 groups; however, compared with the Dex7.5 group, a considerable difference was obtained only on the $28^{\text {th }}$ day. Specifically, neither of the interventions (dexamethasone and citicoline) demonstrated a dose-dependent efficacy on latency time; nonetheless, their beneficial impacts on MDA and TAC levels were dosedependent.

Conventional pharmacological treatments for CisIPN, including tricyclic antidepressants, some anticonvulsants (pregabalin and gabapentin), opioids, and non-steroidal anti-inflammatory drugs, present various side effects, and their efficacy remain unclear. Significantly, inflammation, oxidative stress, altered calcium channel activity, mitochondrial damage, and serotonergic system is associated mechanisms identified in developing CisIPN. ${ }^{24}$

In a study by Takasaki et al. ${ }^{25}$ which examined the antagonist effects of glucocorticoid receptors on allodynia and hyperalgesia in mice-induced neuropathic pain, their results showed that dexamethasone exerted its anti-inflammatory and immunosuppressive effects via spinal glucocorticoid receptors that play a beneficial target in treating peripheral

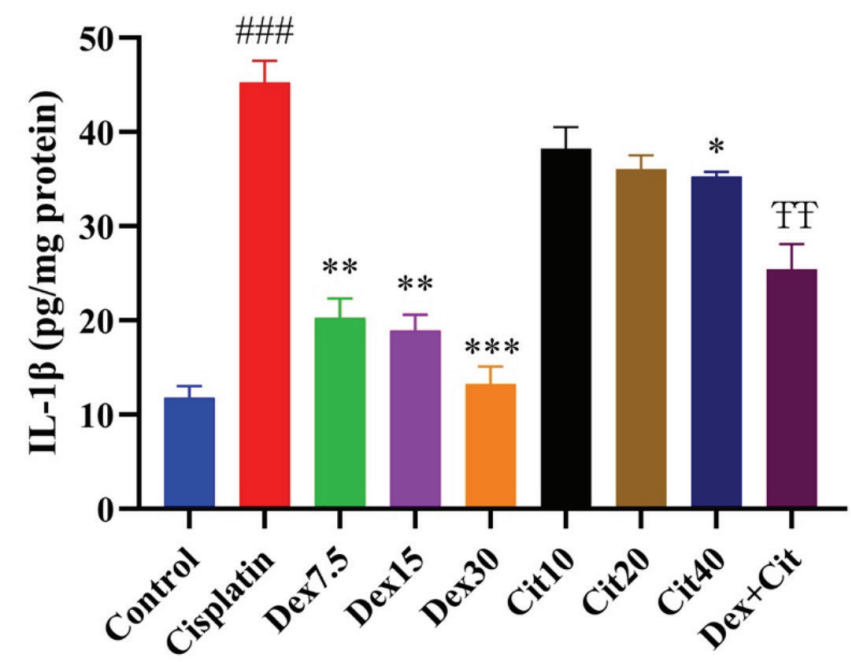

\section{Groups}

Figure 4. The IL-1 $\beta$ levels in different groups. Data are provided as mean \pm SEM (n: 8/each group)

${ }^{*} p<0.05,{ }^{* *} p<0.01$, and ${ }^{* * *} p<0.001$ compared with the cisplatin group. ${ }^{\# \# \#} p<0.001$ as compared with the control group. ${ }^{\mp} p<0.01$ as compared with the Cit10 group, Dex: Dexamethasone, Cit: Citicoline, Dex + Cit: Dexamethasone $7.5 \mathrm{mg} / \mathrm{kg}$ and citicoline $10 \mathrm{mg} / \mathrm{kg}$, SEM: Standard error of means, IL-1 $\beta$ : Interleukin-1 beta neuropathy. A meta-analysis study, which included 32 studies (2.697 patients), presented that dexamethasone partnered dosing could decline bortezomib-IPN severity. ${ }^{26}$ Moattari et al. ${ }^{27}$ found that dexamethasone enhanced sciatic nerve function, regeneration, and histomorphological characteristics followed by sciatic nerve dissection surgery. Additionally, retrospective analyses that included 190 patients demonstrated that dexamethasone could diminish CIPN severity. ${ }^{28}$ Findings from a systematic review of dexamethasone combination therapy with thalidomide (12 studies, including 451 patients with multiple myeloma) indicated that dexamethasone could significantly reduce peripheral neuropathy. ${ }^{29}$

Numerous studies have implied that citicoline demonstrates its neuroprotective properties by increasing sirtuin-1, ${ }^{30,31}$ acetylcholine, ${ }^{32,33}$ and serotonin, ${ }^{34}$ decreasing glutamate levels, ${ }^{17}$ anti-inflammation activity via blocking phospholipase $A 2$, and diminishing reactive oxygen species generation. ${ }^{14}$ Besides, in an experiment using Bagdas et al. ${ }^{35}$, they used the Randall-Sellito test to evaluate the pain threshold, which citicoline significantly elevated the pain threshold through central opioid receptors in a neuropathic pain rat model.

TAC has been used to determine antioxidant activity and response to generated free radicals in particular diseases. Low TAC levels could also be inferred from oxidative stress or enhanced exposure to oxidative stress-induced tissue injuries. ${ }^{36}$ Additionally, MDA levels have been measured as the primary lipid peroxidation indicator, and its elevated levels are associated with cell damages. ${ }^{37}$ Therefore, measuring TAC and MDA are essential factors for assessing the proposed interventions on CisIPN. Kamisli et al. ${ }^{38}$ demonstrated that cisplatin triggered lipid peroxidation and diminished antioxidant defense mechanisms in the brain and sciatic nerve. In this study, cisplatin-enhanced MDA and reduced TAC levels may have induced decrement in antioxidant nerve cells' capacity. Alternatively, dexamethasone and citicoline in the relevant groups elevated TAC and diminished MDA levels compared with control and cisplatin groups, which exert profitable outcomes on CisIPN through antioxidant activities.

Considering the glucocorticoids' catabolic impact of on skeletal muscle, ${ }^{39}$ it is not surprising that the Dex30 group (dexamethasone $30 \mathrm{mg} / \mathrm{kg}$ ) demonstrated the lowest $\Delta \mathrm{W}$ compared with other study groups. Moreover, the $\Delta \mathrm{W}$ lessened in all cisplatin-treated groups (groups 2-9) compared with the control group, implying the induced weight loss by cisplatin in the above groups. Precisely, cisplatin activates the central nucleus of the amygdala, lateral parabrachial nucleus, and nucleus tractus solitarius neurons'; these regions may trigger weight loss through CGRP/glutamatergic signaling. ${ }^{40}$ However, it remains unclear in the current study whether citicoline administration (Cit10, Cit20, Cit40, and Dex + Cit groups) presented a more diminished $\Delta \mathrm{W}$ than the cisplatin group. Besides, we have not found any study that showed citicoline could attenuate body weights; interestingly, some studies have revealed that citicoline mitigated body weight loss. ${ }^{41,42}$ 
It has been indicated that proinflammatory cytokines such as IL-1 $\beta$ and TNF- $\alpha$ play a significant role in cisplatin-induced vestibular damage. ${ }^{43}$ Also, their expression increased in cisplatininduced peripheral nerve injuries, contributing to peripheral neuron excitability and sensitization by mediating tetrodotoxinresistant sodium channels in nociceptors.44,45 Following immune cell activation, IL-1 $\beta$ and TNF- $\alpha$ generate inflammation, they contribute to the development of peripheral sensitization by producing nerve growth factor and prostaglandin $E_{2}$, which triggers pain hypersensitivity in nociceptor dorsal root ganglion neurons. Therefore, inhibiting the synthesis or development of $\mathrm{IL}-1 \beta$ and TNF- $\alpha$ exerts anti-inflammatory impacts and acts as an analgesic against inflammatory pain. ${ }^{46}$ Our results demonstrated that cisplatin elevated IL-1 $\beta$ and TNF- $\alpha$ levels, and administration of dexamethasone and citicoline attenuated them in the treatment groups (Dex7.5, Dex15, Dex30, Cit10, Cit20, Cit40, and Dex + Cit), suggesting that they have potential activity against CisIPN.

This study revealed that cisplatin-enhanced MDA, TNF- $\alpha$, and IL-1 $\beta$ levels; and it declined TAC and pain hypersensitivity; nevertheless, in the treatment groups, MDA and proinflammatory cytokines (IL-1 $\beta$ and TNF- $\alpha$ ) diminished, and TAC and hypersensitivity to pain were elevated. The neuroprotective effect of dexamethasone and citicoline appears to be conferred via anti-inflammatory (declining IL-1 $\beta$ and TNF- $\alpha$ levels) and antioxidant (enhancing the antioxidative capacity and diminishing lipid peroxidation) activities. To our knowledge, this was the first attempt to apply dexamethasone and citicoline in CisIPN, and the evaluation of these two medications is assumed to be novel because they have not been administered for treating CisIPN.

\section{CONCLUSION}

The most critical finding of this research is that dexamethasone and citicoline administration, along with cisplatin, increased the latency time and TAC, declined TNF- $\alpha$ and IL- $1 \beta$, and attenuated lipid peroxidation by reduced MDA levels. We observed that the relevant groups' proposed interventions were better than the control and cisplatin groups in all experiments. The experimental results conclude that since dexamethasone and citicoline have beneficial neuroprotective effects on CisIPN fundamental mechanisms, of clinical studies should be conducted to validate these effects in patients with CisIPN symptoms.

\section{ACKNOWLEDGMENTS}

The authors sincerely acknowledge the staff of Pharmacology Laboratory at Faculty of Pharmacy, Tabriz University of Medical Sciences, for supporting this study.

\section{Ethics}

Ethics Committee Approval: The study protocols and methods were authorized by Tabriz University of Medical Sciences Ethics Committee (ethical code: IR.TBZMED.VCR.REC.1398.087, May 13, 2019), conformed to the NIH Guide for the Care and Use of Laboratory Animals (8 $8^{\text {th }}$ edition, NRC 2011).

Informed Consent: Not applicable.
Peer-review: Externally peer-reviewed.

\section{Authorship Contributions}

Surgical and Medical Practices: F.M., Y.A., Concept: F.M., Y.A., J.M., Design: F.M., B.H.A., Data Collection or Processing: F.M., M.C., Analysis or Interpretation: F.M., B.H.A., Literature Search: F.M., Writing: F.M.

Conflict of Interest: No conflict of interest was declared by the authors.

Financial Disclosure: The authors declared that this study received no financial support.

\section{REFERENCES}

1. Authier N, Fialip J, Eschalier A, Coudoré F. Assessment of allodynia and hyperalgesia after cisplatin administration to rats. Neurosci Lett. 2000;291:73-76.

2. Seretny M, Currie GL, Sena ES, Ramnarine S, Grant R, MacLeod MR, Colvin LA, Fallon M. Incidence, prevalence, and predictors of chemotherapy-induced peripheral neuropathy: a systematic review and meta-analysis. Pain. 2014;155:2461-2470.

3. Glare PA, Davies PS, Finlay E, Gulati A, Lemanne D, Moryl N, Oeffinger KC, Paice JA, Stubblefield MD, Syrjala KL. Pain in cancer survivors. J Clin Oncol. 2014;32:1739-1747.

4. Streckmann F, Hess V, Bloch W, Décard BF, Ritzmann R, Lehmann HC, Balke M, Koliamitra C, Oschwald V, Elter T, Zahner L, Donath L, Roth $\mathrm{R}$, Faude $\mathrm{O}$. Individually tailored whole-body vibration training to reduce symptoms of chemotherapy-induced peripheral neuropathy: study protocol of a randomised controlled trial-VANISH. BMJ Open. 2019;9:e024467.

5. Li JQ, Chen SR, Chen H, Cai YQ, Pan HL. Regulation of increased glutamatergic input to spinal dorsal horn neurons by mGluR5 in diabetic neuropathic pain. J Neurochem. 2010;112:162-172.

6. Carozzi VA, Marmiroli P, Cavaletti G. The role of oxidative stress and anti-oxidant treatment in platinum-induced peripheral neurotoxicity. Curr Cancer Drug Targets. 2010;10:670-682.

7. Cavaletti G, Pezzoni G, Pisano C, Oggioni N, Sala F, Zoia C, Ferrarese C, Marmiroli P, Tredici G. Cisplatin-induced peripheral neurotoxicity in rats reduces the circulating levels of nerve growth factor. Neurosci Lett. 2002;322:103-106.

8. So H, Kim H, Lee JH, Park C, Kim Y, Kim E, Kim JK, Yun KJ, Lee KM, Lee HY, Moon SK, Lim DJ, Park R. Cisplatin cytotoxicity of auditory cells requires secretions of proinflammatory cytokines via activation of ERK and NF-kappaB. J Assoc Res Otolaryngol. 2007;8:338-355.

9. Bernhardson BM, Tishelman C, Rutqvist LE. Chemosensory changes experienced by patients undergoing cancer chemotherapy: a qualitative interview study. J Pain Symptom Manage. 2007;34:403412.

10. Kolb NA, Smith AG, Singleton JR, Beck SL, Stoddard GJ, Brown S, Mooney $K$. The association of chemotherapy-induced peripheral neuropathy symptoms and the risk of falling. JAMA Neurol. 2016;73:860-866.

11. Al Moundhri MS, Al-Salam S, Al Mahrouqee A, Beegam S, Ali BH. The effect of curcumin on oxaliplatin and cisplatin neurotoxicity in rats: some behavioral, biochemical, and histopathological studies. J Med Toxicol. 2013;9:25-33.

12. Chtourou Y, Gargouri B, Kebieche M, Fetoui H. Naringin abrogates cisplatin-induced cognitive deficits and cholinergic dysfunction through 
the down-regulation of AChE expression and iNOS signaling pathways in hippocampus of aged rats. J Mol Neurosci. 2015;56:349-362.

13. Guindon J, Deng L, Fan B, Wager-Miller J, Hohmann AG. Optimization of a cisplatin model of chemotherapy-induced peripheral neuropathy in mice: use of vitamin $C$ and sodium bicarbonate pretreatments to reduce nephrotoxicity and improve animal health status. Mol Pain. 2014;10:56.

14. Adibhatla RM, Hatcher JF. Citicoline decreases phospholipase A2 stimulation and hydroxyl radical generation in transient cerebral ischemia. J Neurosci Res. 2003;73:308-315.

15. Gonzalez-Rodriguez PJ, Li Y, Martinez F, Zhang L. Dexamethasone protects neonatal hypoxic-ischemic brain injury via L-PGDS-dependent PGD2-DP1-pERK signaling pathway. PLoS One. 2014;9:e114470.

16. Han SR, Yeo SP, Lee MK, Bae YC, Ahn DK. Early dexamethasone relieves trigeminal neuropathic pain. J Dent Res. 2010;89:915-920.

17. Hurtado O, Moro MA, Cárdenas A, Sánchez V, Fernández-Tomé P, Leza JC, Lorenzo P, Secades JJ, Lozano R, Dávalos A, Castillo J, Lizasoain I. Neuroprotection afforded by prior citicoline administration in experimental brain ischemia: effects on glutamate transport. Neurobiol Dis. 2005;18:336-345.

18. Jasielski P, Piędel F, Piwek M, Rocka A, Petit V, Rejdak K. Application of citicoline in neurological disorders: a systematic review. Nutrients. 2020;12:3113.

19. Sun WH, He F, Zhang NN, Zhao ZA, Chen HS. Time dependent neuroprotection of dexamethasone in experimental focal cerebral ischemia: the involvement of NF-kB pathways. Brain Res. 2018;1701:237-245.

20. Bannon AW, Malmberg AB. Models of nociception: hot-plate, tail-flick, and formalin tests in rodents. Curr Protoc Neurosci. 2007; chapter 8: unit 8.9.

21. Miller NJ, Rice-Evans C, Davies MJ, Gopinathan V, Milner A. A novel method for measuring antioxidant capacity and its application to monitoring the antioxidant status in premature neonates. Clin Sci (Lond). 1993;84:407-412.

22. Ohkawa H, Ohishi N, Yagi K. Assay for lipid peroxides in animal tissues by thiobarbituric acid reaction. Anal Biochem. 1979;95:351-358.

23. Najafi M, Noroozi E, Javadi A, Badalzadeh R. Anti-arrhythmogenic and anti-inflammatory effects of troxerutin in ischemia/reperfusion injury of diabetic myocardium. Biomed Pharmacother. 2018;102:385-391.

24. Sisignano M, Baron R, Scholich K, Geisslinger G. Mechanism-based treatment for chemotherapy-induced peripheral neuropathic pain. Nat Rev Neurol. 2014;10:694-707.

25. Takasaki I, Kurihara T, Saegusa H, Zong S, Tanabe T. Effects of glucocorticoid receptor antagonists on allodynia and hyperalgesia in mouse model of neuropathic pain. Eur J Pharmacol. 2005;524:80-83.

26. Kumar SK, Laubach JP, Giove TJ, Quick M, Neuwirth R, Yung G, Rajkumar SV, Richardson PG. Impact of concomitant dexamethasone dosing schedule on bortezomib-induced peripheral neuropathy in multiple myeloma. Br J Haematol. 2017;178:756-763.

27. Moattari M, Moattari F, Kaka G, Mohseni Kouchesfehani H, Sadraie $\mathrm{SH}$, Naghdi M, Mansouri K. Evaluation of dexamethasone treated mesenchymal stem cells for recovery in neurotmesis model of peripheral nerve injury. Neurol Res. 2018;40:1060-1070.

28. Kanbayashi Y, Hosokawa T, Okamoto K, Konishi H, Otsuji E, Yoshikawa T, Takagi T, Taniwaki M. Statistical identification of predictors for peripheral neuropathy associated with administration of bortezomib, taxanes, oxaliplatin or vincristine using ordered logistic regression analysis. Anticancer Drugs. 2010;21:877-881.
29. von Lilienfeld-Toal M, Hahn-Ast C, Furkert K, Hoffmann F, Naumann R, Bargou R, Cook G, Glasmacher A. A systematic review of phase II trials of thalidomide/dexamethasone combination therapy in patients with relapsed or refractory multiple myeloma. Eur J Haematol. 2008;81:247-252.

30. Herskovits AZ, Guarente L. SIRT1 in neurodevelopment and brain senescence. Neuron. 2014;81:471-483.

31. Hurtado O, Hernández-Jiménez M, Zarruk JG, Cuartero MI, Ballesteros I, Camarero G, Moraga A, Pradillo JM, Moro MA, Lizasoain I. Citicoline (CDPcholine) increases sirtuin1 expression concomitant to neuroprotection in experimental stroke. J Neurochem. 2013;126:819-826.

32. Blusztajn JK, Slack BE, Mellott TJ. Neuroprotective actions of dietary choline. Nutrients. 2017;9:815.

33. Synoradzki K, Grieb P. Citicoline: a superior form of choline? Nutrients. 2019;11:1569.

34. Roohi-Azizi M, Torkaman-Boutorabi A, Akhondzadeh S, Nejatisafa AA, Sadat-Shirazi MS, Zarrindast MR. Influence of citicoline on citalopraminduced antidepressant activity in depressive-like symptoms in male mice. Physiol Behav. 2018;195:151-157.

35. Bagdas D, Sonat FA, Hamurtekin E, Sonal S, Gurun MS. The antihyperalgesic effect of cytidine-5'-diphosphate-choline in neuropathic and inflammatory pain models. Behav Pharmacol. 2011;22:589-598.

36. Young IS. Measurement of total antioxidant capacity. J Clin Pathol. 2001;54:339.

37. Parlakpinar H, Tasdemir S, Polat A, Bay-Karabulut A, Vardi N, Ucar M, Acet A. Protective role of caffeic acid phenethyl ester (cape) on gentamicininduced acute renal toxicity in rats. Toxicology. 2005;207:169-177.

38. Kamisli S, Ciftci O, Kaya K, Cetin A, Kamisli O, Ozcan C. Hesperidin protects brain and sciatic nerve tissues against cisplatin-induced oxidative, histological and electromyographical side effects in rats. Toxicol Ind Health. 2015;31:841-851.

39. Bodine SC, Furlow JD. Glucocorticoids and skeletal muscle. Adv Exp Med Biol. 2015;872:145-176.

40. Alhadeff AL, Holland RA, Nelson A, Grill HJ, De Jonghe BC. Glutamate receptors in the central nucleus of the amygdala mediate cisplatininduced malaise and energy balance dysregulation through direct hindbrain projections. J Neurosci. 2015;35:11094-11104.

41. Knippenberg S, Skripuletz T, Rath KJ, Thau N, Gudi V, Pul R, Körner S, Dengler R, Stangel M, Petri S. CDP-choline is not protective in the SOD1G93A mouse model of ALS. Amyotroph Lateral Scler Frontotemporal Degener. 2013;14:284-290.

42. Qian K, Gu Y, Zhao Y, Li Z, Sun M. Citicoline protects brain against closed head injury in rats through suppressing oxidative stress and calpain over-activation. Neurochem Res. 2014;39:1206-1218.

43. Kim HJ, So HS, Lee JH, Park C, Lee JB, Youn MJ, Kim SJ, Yang SH, Lee KM, Kwon KB, Park BH, Park R. Role of proinflammatory cytokines in cisplatininduced vestibular hair cell damage. Head Neck. 2008;30:1445-1456.

44. Elmarakby AA, Sullivan JC. Relationship between oxidative stress and inflammatory cytokines in diabetic nephropathy. Cardiovasc Ther. 2012;30:49-59.

45. Jin X, Gereau RW. Acute p38-mediated modulation of tetrodotoxinresistant sodium channels in mouse sensory neurons by tumor necrosis factor-alpha. J Neurosci. 2006;26:246-255.

46. Binshtok AM, Wang H, Zimmermann K, Amaya F, Vardeh D, Shi L, Brenner GJ, Ji RR, Bean BP, Woolf CJ, Samad TA. Nociceptors are interleukin1beta sensors. J Neurosci. 2008;28:14062-14073. 